be therefore be considered when predicting the development of later skills. There are however other factors which can alter progression of NSAA including behaviour. More research is needed to further understand the impact of hypermobility in the DMD population especially for later years and loss of ambulation.

\section{GENERAL PAEDIATRIC NURSING EDUCATION AT GOSH- NEW TEAM, A NEW DISEASE}

Elizabeth Akers, Sonia Chavda, Chloe Couzens, Louise Eccles, Sophie Grout, Kirsty HartDyer, Danielle Law, Amelia Painter, Summer Parker, Emma Scott. GOSH

\subsection{6/archdischild-2020-gosh.75}

In response to the first wave of the Covid 19 pandemic, the profile of healthcare provision internationally underwent rapid and significant change. At GOSH, we opened several wards to support general paediatric care, enabling partner hospitals across the North Central London STP to increase their adult bed provision. This change in patient profile at GOSH presented many exciting opportunities. As educators, we supported the team to care for a wide variety of patients typically seen in general paediatrics; those with chest infections, diabetes, neonatal jaundice to safeguarding and mental health concerns. We could not have foreseen that a new and complex disease process would emerge. Covid-19 was expected, PIMS-TS brought new challenges; the nursing education needed to meet this challenge.

The education strategy utilised a consistent and systematic approach; putting theory into practice and sharing emerging knowledge as it was identified. Nursing care had to adapt to continue to meet the changing needs of our patients and the teams caring for them.

The nursing team formed to support General Paediatrics at GOSH were an amalgam of teams from across the Trust; primarily International Private Patients, Kingfisher Ward, Outpatients' and the Clinical Research Facility. The risks posed by merging new teams in a new environment with a new specialism are significant. Recognition of the heightened risks of this scenario drove our education strategy and planning. The strategy was one of hands on clinical support underwritten by regular multi-professional teaching.

The General Paediatric Education Team was also an amalgam. This brought together a group of experienced educators, all with some background knowledge of general paediatrics. The challenges and risks of merging teams are always similar; this had to be factored into our rapidly formed education team; working effectively and safely whilst managing existing and new conditions and our own anxiety about Covid-19.

\section{OUTCOMES OF VIRTUAL APPOINTMENTS AT GOSH}

Eve Akintomide, Catherine Peters. Great Ormond Street Hospital

\subsection{6/archdischild-2020-gosh.76}

Background The need to upscale virtual consultations has been made apparent during the COVID pandemic. This study explores the effectiveness of virtual visits.

Method A questionnaire was sent to clinicians about their experience and the effectiveness of face-to-face, video and telephone appointments based on ease of assessment and decision-making. Ethical approval was not required. Survey results were compared to outpatient clinic visit outcomes of June 2019 and June 2020.

Results Survey - Of 95 completed questionnaires, over $75 \%$ reported they were often able to complete a medical and social history and make a diagnosis during virtual visits. Identifying non-verbal cues, ascertaining clinical signs, and starting treatment was more challenging, especially via telephone.

\section{CLINIC VISIT OUTCOMES:}

June'19

Further contact required - 35\% (32\% F2F; 3\% Tel)

Discharge - 6\% (5\% F2F; 1\% Tel)

Decision to Admit - 5\% (5\% F2F; 1\% Tel)

June'20

Further contact required - 46\% (14\% F2F; 21\% Tel; 11\% Vid)

Discharge - 7\% (1\% F2F; 4\% Tel; 2\% Vid)

Decision to admit - 4\% (1\% F2F; 2\% Tel; $1 \%$ Vid)

DNA/WNB OUTCOMES

Further Contact Required

June'19 - 71\% (70\% F2F; 1\% Tel)

June'20 - 81\% (20\% F2F; 43\% Tel; 18\% Video)

Discussion Virtual appointments can be an effective alternative when examination is not required. There was no relationship between decision to admit and appointment type, and the highest percentage of patients were discharged following telephone visits, highlighting that virtual visits may be more appropriate for some patients.

Video visits bridge the gap between face-to-face and telephone appointments, easing the identification of non-verbal cues and clinical signs. Lack of additional cues however may explain why clinicians reschedule more telephone visits following WNB attendances than other visit types.

Conclusion Results suggest that clinicians are able to deliver care virtually in a meaningful manner, allowing for clinical assessment and appropriate decision-making.

\section{A VIRTUAL REALITY: USING SIMULATION AND VIRTUAL TEACHING TOOLS TO CREATE AN EQUITABLE INDUCTION EXPERIENCE FOR NEW TRAINEES}

${ }^{1}$ Rhian Thomas, ${ }^{2}$ Shereen Tadros, ${ }^{2}$ Elisabeth Rosser, ${ }^{3}$ Emily Sloper, ${ }^{4}$ Rachel Jones, ${ }^{1}$ Helena Carley, ${ }^{3}$ Alexandra Murray, ${ }^{1}$ Kate Tatton-Brown, ${ }^{2}$ Linda Chigaru. ${ }^{1}$ St George's, University of London; ${ }^{2}$ GOSH; ${ }^{3}$ Institute of Medical Genetics for UK; ${ }^{4}$ Guy's Hospital

\subsection{6/archdischild-2020-gosh.77}

Background Clinical genetics is a small specialty with around 70 trainees nationally. New trainees traditionally have a period of observing clinics led by consultants and experienced genetic counsellors before leading their own clinic. This is an important time in which they learn practical and communication skills with respect to approaching a consultation, however, the experience can be variable dependent on the centre.

In light of the coronavirus pandemic, knowing that many new trainees would not be able to access this vital induction period, we devised a virtual induction programme.

Methods A group of clinical geneticists from three UK centres, including GOSH, worked in collaboration with the GOSH Clinical Simulation Team to devise and deliver a programme that would be accessible to all new trainees. Important topics for discussion were agreed; example consultations were filmed, with the help of actors; and trainee simulations were planned. 